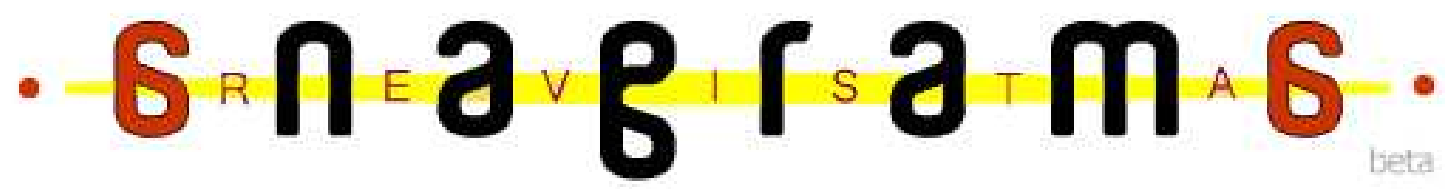

\section{notícias Sobre Meio Ambiente no Jornal 0 Alto Uruguai: análise de conteúdo e de conotação da mensagem no primeiro semestre de 2012}

Karine Ruviaro ${ }^{1}$

Uandressa Garzont

Cláudia Herte de Moraes ${ }^{3}$

\section{Resumo}

$\mathrm{O}$ artigo apresenta resultados parciais do projeto Jornalismo de meio ambiente no Médio Alto Uruguai que tem o objetivo de identificar a abordagem do tema nas publicações da região. Com a metodologia da análise de conteúdo, aborda as categorias do conteúdo explícito do texto e da conotação da mensagem, a partir das notícias do jornal $O$ Alto Uruguai, publicado em Frederico Westphalen, no primeiro semestre de 2012. Conclui-se que a prática do jornalismo ambiental ainda é pouco explorada, principalmente em um jornal do interior, pois foram encontrados apenas 35 registros no período estudado. No aspecto do conteúdo da mensagem, houve predomínio de atividades públicas enquanto que o aspecto ambiental foi preponderante na conotação das mensagens coletadas.

Palauras-chaue: Jornalismo Ambiental; Jornal O Alto Uruguai; Frederico Westphalen

Introdução

A pesquisa aqui relatada parte do princípio de que o Jornalismo Ambiental deve ser entendido a partir de seu crescente papel e importância na sociedade. Por isso, se propõe a

1Estudante de Graduação $3^{\circ}$ Semestre do Curso de Jornalismo da Universidade Federal de Santa Maria, UFSM - Frederico Westphalen. E-mail: kakasruviaro@ hotmail.com

2 Estudante de Graduação $3^{\circ}$ Semestre do Curso de Jornalismo da Universidade Federal de Santa Maria, UFSM -Frederico Westphalen. E-mail: vandi.garzon@ hotmail.com

3Orientadora da pesquisa. Jornalista. Doutoranda em Comunicação e Informação (UFRGS). Professora do curso de Comunicação Social - Jornalismo, UFSM-Frederico Westphalen. E-mail: chmoraes@gmail.com 
busca do aprofundamento dos estudos sobre esta temática. (Moraes, 2008). O meio ambiente é pauta nas denúncias de desmatamento e desastres diversos, porém há muito destaque para o enfoque do entretenimento e do alarme, e pouco se reflete sobre causas e consequências. Nas análises da cobertura ambiental, verifica-se a falta de espaços na mídia para os problemas da área. (Girardi, 2010). Também se salienta complexidade do tema, que envolve interesses políticos e econômicos, além de uma necessária formação do jornalista na apuração das informações utilizadas (Moraes e Corrêa, 2008).

Por outro lado, aponta-se que o texto jornalístico deve estar bem escrito e informar seu público, sendo esta a função principal do jornalismo. Porém, quando o tema é o futuro do planeta, o objetivo do jornalismo parece ser ainda maior, pois se inclui também a ideia de uma educação para a melhoria da qualidade de vida a partir de escolhas sustentáveis. (Girardi, 2006). Assim, nosso objetivo é analisar que tipo de mensagem ambiental é trazida para a comunidade a partir do jornal estudado e quais as conotações existentes?

$\mathrm{O}$ artigo apresenta parte inicial dos resultados das análises do projeto intitulado Jornalismo de meio ambiente no Médio Alto Uruguai que investiga como as notícias ${ }^{4}$ sobre meio ambiente são apresentadas pelos jornais da cidade de Frederico Westphalen, que atingem a região do Médio Alto Uruguai no Rio Grande do Sul. O recorte realizado para este relato são as notícias publicadas no jornal $O$ Alto Uruguai, publicado em Frederico Westphalen (RS), no primeiro semestre de 2012.

\section{Jornalismo ambiental}

A urgência do debate social em torno das questões ambientais em certa medida não é acompanhada pelo conjunto dos meios de comunicação. Por esta necessidade, no Brasil, desde o início dos anos 1990, jornalistas ambientais passam a constituir grupos de ecojornalistas, que buscam a prática de um jornalismo comprometido com os problemas ambientais. $\mathrm{Na}$ área acadêmica, também se constituem grupos de pesquisa e aos poucos ganham espaço nos programas de pós-graduação.

Para Bueno (2007) o jornalismo ambiental passa por um processo de amadurecimento. $\mathrm{O}$ autor acredita que o conceito deste jornalismo tem que ter seu próprio

4 "Notícia é uma representação social da realidade cotidiana produzida institucionalmente e que se manifesta na construção de um mundo possível" (ALSINA, 1996, p.185). 
significado, nem que para isto necessite integrar com outros tipos de jornalismo especializado.

Jornalismo ambiental é entendido como "a inserção da visão ambiental tendo com pano de fundo a possibilidade da sustentabilidade" (Girardi, 2006: 9). Os autores apontam que o jornalismo ambiental segue os preceitos do jornalismo "mas reforça a exploração de dados, a apuração, as ligações que envolvem o fato noticiado, suas consequências e origens, (...) fornece evidências, diagnósticos que ajudam na construção de um saber ambiental necessários à vida cotidiana" (Girardi e Schwaab, 2008:17-18).

Entendemos que o jornalismo ambiental é um jornalismo especializado, porém, como afirma Bueno (2007), ele tem um compromisso maior com o interesse público, e com a democratização do conhecimento. A preocupação do autor é de que o jornalismo sirva como porta-voz dos segmentos já privilegiados socialmente. "O jornalismo ambiental, como o saber ambiental, não é propriedade dos que detêm o monopólio da fala, mas deve estar, umbilicalmente, sintonizando com o pluralismo e a diversidade" (Bueno, 2007:14).

Para Bueno (2007), mais que noticiar problemas, o jornalismo ambiental precisa ser comprometido com a mudança:

[...] precisa ter um caráter revolucionário, comprometido com a mudança de paradigmas, deve enxergar além das aparências e não ser complacente com aqueles que se apropriaram da temática ambiental para formar ou reforçar a imagem. Deve suspeitar sempre do discurso pretensamente preservacionista de governos e organizações, buscando completar além de ações isoladas, quase sempre utilizadas como recursos mercadológicos ou propagandísticos. (Bueno, 2007:17)

Bueno (2007) aponta que o jornalismo ambiental é militante no sentido de compromisso com "o interesse público, com a democratização do conhecimento, com a ampliação do debate" (Bueno, 2007:14). Para isso é preciso investigar causas e consequências, e ser aliado da qualidade de vida dos cidadãos. "Uma das premissas do jornalismo ambiental é perceber a realidade que nos cerca de um ângulo mais abrangente, privilegiando a qualidade de vida no planeta e do planeta" (Trigueiro, 2008:81).

Trigueiro (2008) enfatiza que o jornalismo ambiental movimenta vários setores sociais, com oportunidade de mobilizar a população a partir do debate através dos meios de comunicação. Para Bueno (2007), a militância necessária do jornalismo ambiental começa com o domínio de conceitos básicos além de o jornalista buscar a crítica contextualizando e politizando este debate. 
O jornalismo ambiental deve propor-se política, social e culturalmente engajado, porque só desta forma conseguirá encontrar forças para resistir às investidas e pressões de governos, empresas e até de universidades e institutos de pesquisa, muitos deles patrocinados ou reféns dos grandes interesses. (Bueno, 2007: 29)

Por isso, concordamos com Baccheta (2008) que diz ser o jornalismo ambiental "um jornalismo que procura desenvolver a capacidade das pessoas para participar e decidir sobre seu modo de vida na Terra, para assumir em definitivo sua cidadania planetária" (Bacchetta, 2000:18). O autor atribui contribuição essencial do jornalismo na difusão de temas complexos, com a análise de suas implicações de ordem políticas, éticas, sociais e culturais.

$\mathrm{O}$ questionamento feito pela pesquisa em andamento toma por base o conceito amplamente difundido do desenvolvimento sustentável que é definido pelo relatório da ONU, chamado Nosso Futuro Comum como "o desenvolvimento que encontra as necessidades atuais sem comprometer a habilidade das futuras gerações de atender suas próprias necessidades".

Com isso, são estabelecidos os propósitos de respeito à proteção ambiental, mas passa a ser considerado um desenvolvimento amplo, apoiado na dimensão econômica e social. Para o jornalismo ambiental é prioridade o atendimento a estas dimensões de sustentabilidade, pois não é possível apresentar apenas os ganhos econômicos caso haja depredação ambiental, tampouco a destruição de culturas ou desrespeito às comunidades. Segundo Bueno (2007), o desenvolvimento sustentável tem relação direta com a qualidade de vida e, para o jornalismo ambiental, é muito mais amplo que a vertente econômica do crescimento ou do puro desenvolvimento.

Deste modo, o presente artigo pretende colaborar no entendimento de como se dá a construção da notícia ambiental, levando-se em conta os novos paradigmas da sustentabilidade. Entendemos o jornalismo a partir das teorias da construção social da notícia, pois são muitos os elementos envolvidos na prática cotidiana de transformar acontecimentos sociais em fatos notáveis, há interações entre os agentes sociais e os jornalistas. Por isso, conforme Traquina (2005), a "construção" da notícia está no centro da disputa de um saber especializado, exercido pelos jornalistas.

A partir destes pressupostos teóricos, questionamos sobre a abordagem das notícias sobre meio ambiente em nossa região: será que os jornais regionais e de cidades menores 
incorporam esta preocupação ambiental? Como aparecem as questões econômicas e políticas? São predominantes em relação ao ambiental?

\section{Metodologia utilizada}

A pesquisa faz a análise do jornal $O$ Alto Uruguai, que é o principal periódico impresso da região, e o mais antigo jornal de Frederico Westphalen. Fundado em 1965, a Empresa Jornalística Jornal $O$ Alto Uruguai conta com mais de cinco mil assinantes, distribuídos em 22 municípios da região ${ }^{5}$, com uma tiragem média de seis mil exemplares por edição. Semanalmente, são editadas, em média, 90 páginas, sendo aproximadamente 30 páginas nas quartas-feiras e 60 páginas nos sábados.

Para estudar as notícias sobre meio ambiente apresentadas pelo jornal $O$ Alto Uruguai foi utilizada a metodologia da Análise de Conteúdo (AC). Com isso, pretende-se fazer o levantamento de várias características sobre a informação ambiental, tais como origem das notícias, temas mais usados, formas de utilização da imagem entre outros. Neste artigo, o recorte realizado apresenta os itens referentes ao conteúdo, em duas características que são interrelacionadas: Conteúdo da mensagem e Conotação da mensagem.

A definição metodológica apoia-se na definição de Fonseca Júnior (2006), que indica que o método de $\mathrm{AC}$ é “destinado à investigação de fenômenos simbólicos por meio de várias técnicas de pesquisa. Assim, a análise de conteúdo, tem por objetivo extrair conhecimentos sobre os aspectos latentes da mensagem analisada." (Fonseca Junior, 2006:280-283).

Para os estudos de jornalismo, é considerado um método adequado e muito utilizado, pois permite que sejam recolhidos e analisados:

[...] textos, sons, símbolos e imagens impressas, gravadas ou veiculadas em forma eletrônica ou digital encontradas na mídia a partir de uma amostra aleatória ou não dos objetos estudados com o objetivo de fazer inferências sobre seus conteúdos e formatos enquadrando-os em categorias previamente testadas, mutuamente exclusivas e passíveis de replicação. (Herscovitz, 2007:123-126).

5 "Na região do Médio Alto Uruguai, encontram-se 34 municípios que, juntos, somam 188.772 habitantes segundo dados da Federação Economia e Estatística do Rio Grande do Sul, em levantamento realizado em 2004 e publicado no Planto Territorial de Desenvolvimento Rural Sustentável (2006). Esta população está dividida com cerca de $52 \%$ ainda na zona rural e a principal atividade é a agrícola como geradora da economia, representando 58\% da renda média dos municípios” (MORAES, 2007). 
A coleta de dados se deu no período de $1^{\circ}$ de janeiro de 2012 a 31 de julho de 2012. Escolheu-se o primeiro semestre de 2012, pois neste período haveria a preparação do evento da Rio + 20 (Conferência das Nações Unidas sobre o Desenvolvimento Sustentável), que teve por objetivo renovar e reafirmar a participação de líderes de países com relação ao desenvolvimento sustentável na planeta Terra. O evento se realizou no Rio de Janeiro, em junho de 2012, e esta proximidade de datas apresentou-se como hipótese de que haveria maior destaque ao tema ambiental nos meios de comunicação em geral.

\section{Análises e discussão dos resultados}

Conforme explicitamos na metodologia, apresentam-se os resultados iniciais de uma pesquisa com foco no jornal O Alto Uruguai e o foco são as categorias de conteúdo da mensagem e conotação da mensagem, a partir da Análise de Conteúdo. No período de coleta representado pelos primeiros seis meses do ano de 2012, foram encontradas 35 matérias ${ }^{6}$ com informações sobre meio ambiente, compondo a totalidade do corpus da pesquisa.

Para dar início à apresentação de resultados, a Tabela 1 traz os números totais de todas as categorias referentes ao conteúdo da mensagem e à conotação da mensagem.

\section{Tabela 1: Números totais das categorias de análise}

\begin{tabular}{|c|c|c|c|c|}
\hline $\begin{array}{c}\text { Conteúdo da } \\
\text { mensagem }\end{array}$ & Governamental & Ações individuais & Pública & Econômica \\
\hline 35 matérias & 4 & 2 & 28 & 1 \\
\hline $\begin{array}{c}\text { Conotação da } \\
\text { mensagem }\end{array}$ & $\begin{array}{c}\text { Mensagem } \\
\text { econômica }\end{array}$ & $\begin{array}{c}\text { Mensagem } \\
\text { ambiental }\end{array}$ & $\begin{array}{c}\text { Mensagem } \\
\text { política }\end{array}$ & Mensagem neutra \\
\hline 35 matérias & 0 & 22 & 1 & 12 \\
\hline
\end{tabular}

6 Nesta pesquisa chamamos de matéria ou matéria jornalística todo o material jornalístico publicado pelo jornal, ou seja, englobando tanto notas, notícias quanto reportagens. 
O que predominou durante o período analisado foram as reportagens de conotação ambiental e com conteúdo de atividades públicas, ou seja, da chamada sociedade civil. Para facilitar a apresentação ao leitor, separamos as duas categorias e apresentamos inicialmente a composição e análise do conteúdo da mensagem e posteriormente a categoria da conotação da mensagem.

\section{Conteúdo da mensagem}

A categoria "conteúdo da mensagem" está relacionada a diferentes itens como, por exemplo, a ideia, intenções e objetivos que se quer transmitir na notícia, atingindo facilmente o seu público-alvo por ser a comunicação em si. Falamos, em certa medida, de conteúdos manifestos (explícitos), e partimos deles (tal como se manifesta) e não algo que estaria comunicando 'através dele'. Desta forma, os resultados da análise de conteúdo buscam refletir os objetivos da pesquisa, tendo-se como apoio indícios manifestos no conteúdo das comunicações.

Portanto, nesta pesquisa considera-se que o conteúdo da mensagem é um conteúdo manifesto e entendido a partir do conceito de denotação, tal como definem Platão e Fiorin: "A relação existente entre o plano da expressão e o plano do conteúdo. Desse modo, significado de denotativo é aquele conceito que um certo significante evoca no receptor. Em outras palavras, é o conceito ao qual nos remete um certo significante" (Platão \& Fiorin, 2000:113).

Assim, explica-se que a organização da categoria conteúdo da mensagem foi realizada a partir da análise textual, dividindo-se o conjunto das matérias encontradas entre ações de diferentes atores sociais, por isso de conteúdo governamental, individuais, públicas ou do setor econômico.

Em conteúdo governamental encontram-se as notícias sobre ações de órgãos governantes na Região. No conteúdo individual, aparecem informações sobre ações feitas pelos cidadãos de maneira individual, como sobre pequenos agricultores que utilizavam de maneira sustentável os recursos naturais, principalmente os recursos hídricos. No conteúdo de notícias públicas encontram-se matérias referentes ao que está acontecendo atualmente em todas as esferas geográficas, como, por exemplo, na cidade de Frederico Westphalen, Região do Médio Alto Uruguai, Estado e País.

Considera-se ser explicativo apresentarmos trechos de algumas matérias que continham os conteúdos anteriormente mencionados, nas figuras a seguir. 
G estores públicos têm dois anos e meio para preparar a coleta seletiva em suas cidades. De acordo com um ofício encaminhado pela Presidência do Tribunal de Contas do Estado (TCE-S) aos prefeitos, o órgão passará a fiscalizar a implementação das ações relativas ao cumprimento da Política Nacional de Resíduos Sólidos. A política foi instituída pela Lei Federal n ${ }^{\circ} 12.305$, de 2 de agosto de 2010, e regulamentada pelo Decreto ${ }^{\circ} 7.404$.

O presidente do TCE-RS, Cezar Miola, ressaltou no documento que a elaboração do Plano Municipal de Gestão Integrada de Resíduos Sólidos é condição para os municípios terem acesso a recursos da União destinados a empreendimentos e serviços relacionados à limpeza urbana e ao manejo de resíduos sólidos.

No ofício, o presidente destaca, também, que a implantação do sistema de coleta seletiva de lixo deve ser realizada até o dia 3 de agosto de 2014, prazo estabelecido no art. 54 da Lei Federal citada.

$\mathrm{Na}$ região, poucos municípios realizam a coleta seletiva. Outros procuram reativar ou começar novos projetos. Em Frederico Westphalen, a ideia começou a ganhar forma com a elaboração de um plano e com a aquisição de dois caminhões específicos para o serviço, adquirido com o apoio da Fundação Nacional de Saúde (Funasa). Em Seberi, com apoio do Consórcio Intermunicipal de Gestão de Resíduos Sólidos (Cigres), foi dado início ao projeto, previsto para começar efetivamente em março.

Taquaruçu do Sul é modelo

Ilustração 1 - Conteúdo governamental: matéria publicada em 21 de janeiro de 2012

Com relação à Ilustração 1 , mostramos um trecho da matéria publicada no dia 21 de janeiro de 2012 com o seguinte título "TCE-RS irá fiscalizar gestão de resíduos sólidos”, a qual trata do período que os gestores públicos têm para adaptar a coleta seletiva em suas cidades. 
$\mathrm{P}$ romovido pela Revista Ecologia \& Meio Ambiente, em conjunto com a Fundação Estadual de Proteção Ambiental (Fepam) e Secretaria Estadual de Meio Ambiente (Sema), o Prêmio Mérito Ambiental Henrique Luiz Roessler, na sua terceira edição, homenageou 21 empresas ou instituições que se destacam por açôes de sustentabilidade.

Neste seleto grupo está a Creluz, Cooperativa de Geração e Distribuição de Energia Elétrica do Norte Gaúcho, sendo a única instituição do ramo de infraestrutura e energia. Uma comissão

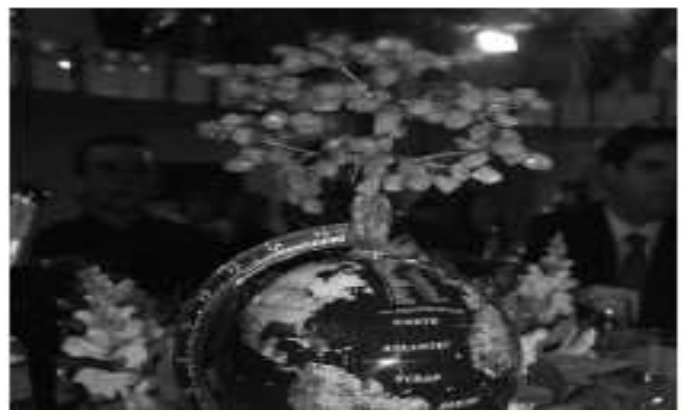

de jurados, formada na maioria por ex-secretários e diretores da Sema e Fepam, analisam os trabalhos ambientais dos indicados ao prêmio e os classificam ou não para receber a distinção. Entre as autoridades, as presencas marcantes da ex-secretária do meio ambiente do Estado, Jussara Cony e do deputado estadual Frederico Antunes.

Em 2012, a solenidade aconteceu no Clube Farrapos, em Porto Alegre, na noite da sexta-feira 29 de junho. O Grupo Creluz esteve representado por uma comissão de colaboradores e membros da direção - diretor tesoureiro Âlvaro Decarli e diretor-secretário Clenio Trentin - receberam o troféu da secretária de Meio Ambiente e Gestão Urbana de Osório, Leda Fammer, sendo cumprimentados pelo jomalista do Grupo RBS, Lasier Martins, que foi o apresentador da cerimônia e leu na solenidade um release dos trabalhos do Grupo Creluz.

Ilustração 2 - Conteúdo setor econômico, matéria publicada em 4 de julho de 2012

A Ilustração 2 mostra matéria que se refere ao conteúdo do setor econômico, e foi publicada pelo jornal no dia 4 de julho de 2012. O título foi "Prêmio Ambiental Henrique Roessler homenageia a Creluz", e a notícia aborda a premiação recebida pela Creluz, apesar de ser um grupo empresarial, as iniciativas de sustentabilidade são promovidas constantemente na empresa, com o enfoque ambiental em primeiro lugar. 
$\mathrm{P}$ romovida através de parceria entre empresas e entidades de Frederico Westphalen, a campanha ambiental "Luz para a vida", que foi lançada oficialmente na semana passada, visa o recolhimento de jornais antigos e lâmpadas fluorescentes.

No dia 14 de julho, os materiais alvos da campanha serão recolhidos entre as 9 horas e as 15 horas, no Largo Vitalino Cerutti (calçadão da praça da matriz). No entanto, quem desejar se antecipar e já eliminar as lâmpadas, po- derá descartá-las adequadamente, durante todo o mês de julho, no turno da tarde, na sede do $2^{\circ}$ Grupamento de Polícia Ambiental, localizado em frente à Prefeitura de Frederico Westphalen.

0 evento será realizado através de parceria entre o $2^{\circ} \mathrm{Gru}-$ pamento de Polícia Ambiental, curso de Ciências Biológicas da URI/FW, Comissão OAB Vai à Escola, jornal 0 Alto Uruguai, Consórcio Intermunicipal de Gestão de Resíduos Sólidos (Cigres) e CDL de Frederico Westphalen.

Ilustração 3 - Conteúdo de iniciativas públicas, matéria publicada em 16 e junho de 2012

A publicação do dia 16 de junho de 2012 feita pelo jornal (Ilustração 3), com o título "Hora de conscientizar", aborda a iniciativa de empresas e entidades de Frederico Westphalen para que a população em geral faça a entrega correta de lâmpadas e jornais velhos.

Apresenta-se a seguir o Gráfico 1 o qual se refere ao conteúdo da mensagem haja vista que conteúdo e conotação da mensagem são definições diferentes. Nesse gráfico, também foram analisadas as 35 matérias vinculadas no jornal Alto Uruguai no período estudado. 


\section{Conteúdo Ambiental no Jornal Alto Uruguai}

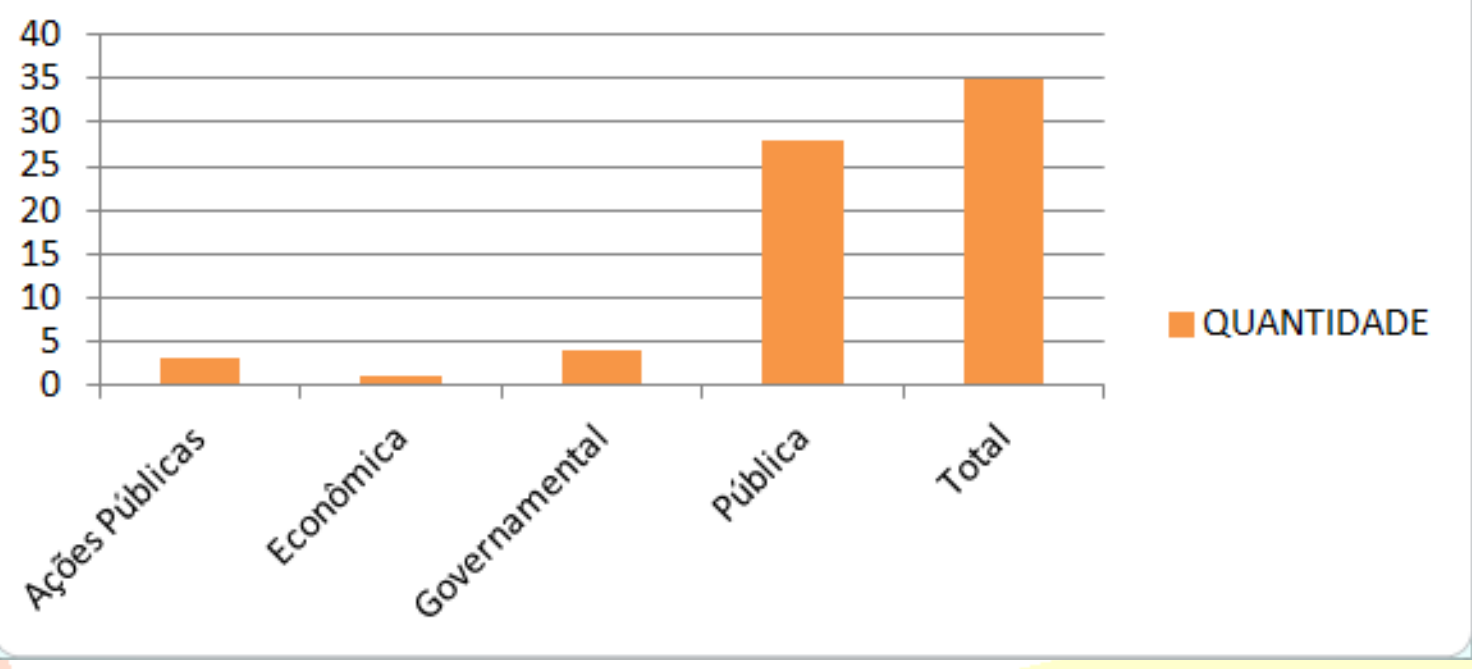

Gráfico 1 - Conteúdo da mensagem

Referente à análise do Gráfico 1, tem-se o seguinte resultado acerca do conteúdo da mensagem. Das 35 matérias analisadas, 28 são de conteúdo público, pois o jornal emite muitas notas/notícias que se referem ao público em geral, principalmente quando são feitas ações que garantem o bem-estar da população do Médio Alto Uruguai.

Em seguida, temos quatro mensagens com conteúdo governamental, pois como a região faz parte de rotas turísticas do Estado, e dentro desse contexto sempre há notícias sobre a melhora nas condições de visitação desses pontos turísticos.

Por fim, aparecem as mensagens de conteúdo referente às ações individuais as quais apenas três tem como enfoque principal a melhor utilização de algum recurso natural já existente na localidade, e traz muitas vezes o produtor rural como personagem principal. Com conteúdo econômico não foi publicada nenhuma mensagem nesta categoria.

Para ilustrar o tipo de notícia ambiental de conteúdo público, a categoria que predominou no corpus da pesquisa, apresentamos a matéria publicada em 16 de junho de 2012, na página 19 do jornal. Nesta reportagem é possível perceber que o conteúdo público refere-se ao chamado 'túnel verde' o qual evita que os galhos das árvores tenham que ser cortados a fim de que não encostem na rede elétrica. O jornal, ao alertar para o problema, atua a serviço do interesse público. 
Em relação ao conteúdo da mensagem, encontramos 28 matérias com o conteúdo público, pois na maior parte dos casos são notas que tendem a mostrar e conscientizar a população do Médio Alto Uruguai quanto a melhor utilização dos recursos naturais, bem como conscientização ambiental.

Nesse contexto, fichamos quatro matérias de conteúdo governamental as quais geralmente trazem comunicados da administração municipal referentes a alguma modificação ou melhoramento na legislação ambiental do município. Matérias referentes ao conteúdo de ações individuais trazem como enfoque principal ações de indivíduos comuns que utilizam de maneira sustentável os recursos naturais.

\section{Conotação da mensagem}

Na coleta de dados dividiu-se a categoria de "conotação da mensagem" a partir dos campos sociais mais voltados à questão do meio ambiente que são a economia, o meio ambiente, a política e também se havia alguma mensagem de conotação neutra, ou seja, que não estava voltada a nenhuma outra categoria anterior. Esta divisão levou em conta a definição do desenvolvimento sustentável em que as dimensões ambientais, econômicas e sociais (políticas) devem ser valorizadas.

Para avaliar os sentidos conotados da mensagem, toma-se como base uma concepção interacional (dialógica) da língua, pois os sujeitos são vistos como atores/construtores sociais, portanto, o texto passa a ser considerado o próprio lugar da interação, e os interlocutores, sujeitos ativos que dialogicamente se constroem e são construídos por intermédio dele (Koch, 2002). Desta forma, no texto coexistem uma gama de implícitos, dos mais variados tipos, somente detectáveis quando se tem, como pano de fundo, o contexto sociocognitivo dos participantes da interação. (Koch, 2002:17)

Nesse contexto, a conotação da mensagem é entendida como:

Um termo ou uma palavra, além do seu significado denotativo, pode vir acrescido de outros significados paralelos, pode vir carregado de impressões, valores afetivos, negativos e positivos. Assim, sobre um signo linguístico, dotado de um plano de expressão e um plano de conteúdo, pode-se construir outro plano de conteúdo constituído de valores sociais, de impressões e reações psíquicas que um signo desperta. Esses valores sobrepostos ao signo constituem aquilo que denominamos de sentido conotativo e esse acréscimo de um novo conteúdo constitui a conotação. (Platão \& Fiorin, 2000:114) 


\section{Conotação da Mensagem no Jornal Alto Uruguai}

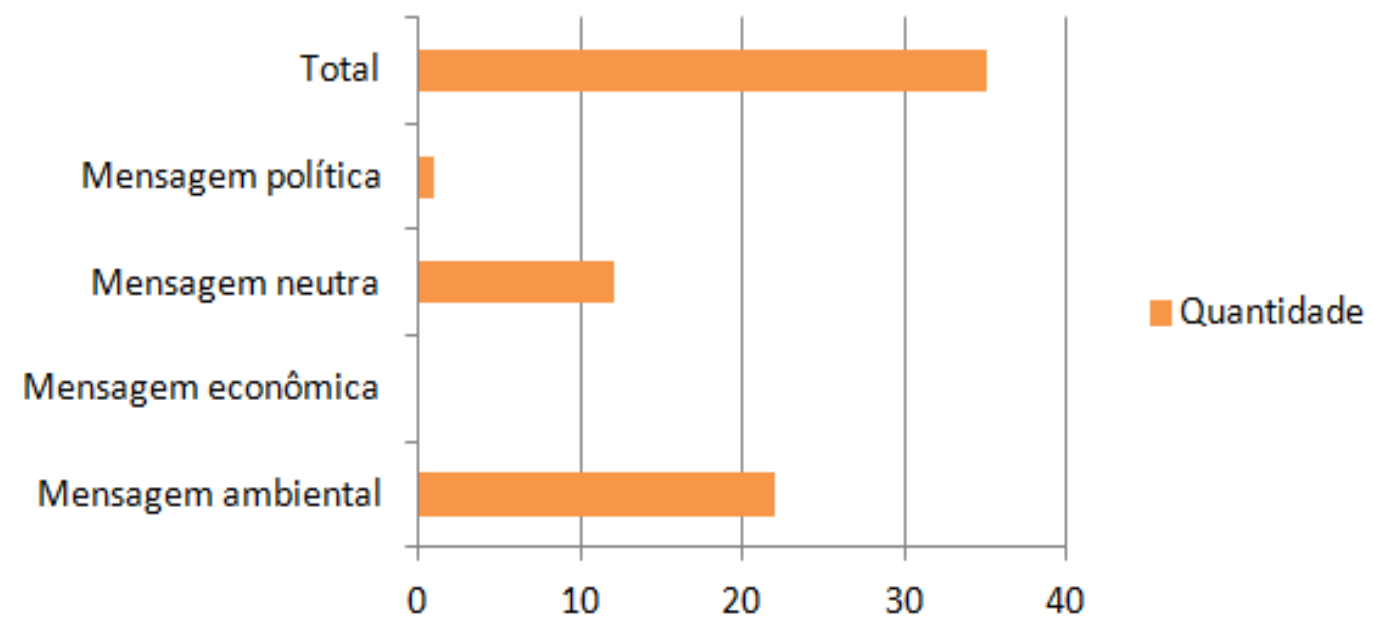

Gráfico 2 - Conotação da Mensagem

A partir da análise do Gráfico 2, pode-se perceber que referente à conotação da mensagem, 22 matérias utilizavam a mensagem ambiental como conotação principal, em seguida temos 12 mensagens neutras e por fim uma mensagem com conotação política e nenhuma referente à mensagem econômica.

Grande parte das mensagens serem de cunho ambiental podem ser explicadas pelo tipo de notícia produzida na região de cobertura, que aponta para as atividades de educação ambiental e encontros em escolas e instituições na região, além das notícias sobre conservação e preservação ambiental, bem como desenvolvimento sustentável.

Para exemplificar a conotação ambiental, citamos o trecho da reportagem de 26 de janeiro de 2012 publicada na página 6 do jornal O Alto Uruguai: "Apreciar a natureza, colaborar para a sua preservação e também aprender um pouco mais sobre o meio ambiente são alguns dos motivos que levam diversas pessoas a optar por fazer trilhas, programa que, inclusive, proporciona bem-estar e diversão".

Assim, percebe-se com a análise que 22 matérias referiam-se à conotação ambiental pelo fato de o jornal $O$ Alto Uruguai veicular matérias com o objetivo de preservação e conservação ambiental, bem como sobre desenvolvimento sustentável.

O segundo maior enfoque do jornal estudado deu-se por matérias com conotação neutra, que visam informar à população sobre iniciativas que objetivam melhorar o 
ambiente social, porém sem direcionar o entendimento para nenhuma das categorias analisadas.

A conotação política apareceu com o total de apenas duas matérias, as quais se referem a ações de âmbito municipal, estadual e federal com o objetivo principal de regularizar o funcionamento de órgãos que utilizam o meio ambiente como principal matéria-prima.

\section{Considerações finais}

Tentando responder ao questionamento sobre como as notícias ambientais são apresentadas no jornal de uma cidade do interior do Rio Grande do Sul, partimos da ideia de que os meios de comunicação e seu papel simbólico são fundamentais para a mudança necessária em nosso modo de vida. E esta responsabilidade pelo que é publicado atinge especialmente os jornalistas.

Cabe ressaltar que o tema ambiental apresenta-se em constante crescimento, tanto na comunidade científica, quanto nas comunidades em geral, haja vista que esse fato foi bastante impulsionado devido à elaboração de agendas internacionais propostas pela Organização das Nações Unidas (ONU).

A partir do levantamento da publicação de notícias sobre meio ambiente no Jornal o Alto Uruguai, o principal meio impresso da Região do Médio Alto Uruguai, a análise de conteúdo mostrou que o tema ambiental não foi tão abundante quanto à hipótese inicial da pesquisa, de que a proximidade da Rio+20 traria maios incidência de notícias nos jornais brasileiros.

No Jornal $O$ Alto Uruguai, objeto de nossa pesquisa, em seis meses houve apenas 35 matérias sobre o tema ambiental, isso que o material foi considerado com a inclusão de notas e registros pequenos, além de algumas reportagens. Ou seja, podemos concluir que mesmo sendo uma pauta nacional e até mesmo internacional, a Rio+20 parece não ter obtido a repercussão maior em jornais de cidades interioranas.

A partir da Análise de Conteúdo aplicada, pode-se afirmar que a maior parte das matérias se refere a um misto de mensagens ambientais com ênfase as mensagens públicas. Desta forma, podemos caracterizar que as matérias publicadas no jornal contribuem para ampliar a qualidade da informação ambiental e, além disso, dão destaque para a atuação da sociedade civil no processo de conscientização ambiental. 
Por outro lado, os setores políticos e econômicos não aparecem com tanta frequência quanto em grandes jornais os quais normalmente valorizam as iniciativas governamentais e do setor econômico. Isso pode ser também um reflexo do ambiente regional, que parece carecer de iniciativas tanto do chamado setor produtivo quanto dos governos locais e políticos regionais.

Cabe salientar que a notícia ambiental encontrada no jornal $O$ Alto Uruguai, embora ainda em número pequeno frente à necessidade de debate sobre o tema, traz informações importantes sobre as ações que visam à sustentabilidade. Sobre nosso questionamento inicial, aponta diferenças em relação aos grandes jornais, que normalmente dão grande espaço ao setor econômico e empresarial e às ações de governos e fontes oficiais enquanto que, no jornal analisado, as ações públicas e ambientais prevaleceram.

\section{Referências Bibliográficas}

ALSINA, Miguel Rodrigo. La construcción de la noticia. Barcelona: Paidós, 1996.

BACCHETTA, Víctor. "El periodismo ambiental". In BACCHETTA, Vítor Leteo (org.). Ciudadanía planetária: temas y desafios para El periodismo ambiental. Montevidéu: IFEJ, 2000 .

BUENO, Wilson da Costa. Comunicação, Jornalismo e Meio Ambiente: teoria e pesquisa. São Paulo: Mojoara Editorial, 2007.

CAMPOS, Claudinei. José. Gomes. Método de análise de conteúdo: ferramenta para a análise de dados qualitativos no campo da saúde.

http://www.scielo.br/pdf/reben/v57n5/a19v57n5.pdf. Acessado em 03 mai.2013. 
FONSECA JUNIOR, Wilson. Correa. “Análise de conteúdo”. In DUARTE, Jorge.;

BARROS, Antonio (org.). Métodos e técnicas de pesquisa em comunicação. São Paulo:

Atlas, 2006.

GIRARDI, Ilza Maria Tourinho; MASIERER, Carine; SCHWAAB, Reges Toni. Pensando o jornalismo ambiental na ótica da sustentabilidade. Unirevista, São Leopoldo, no.3/Julho de 2006, pp.1-12

SCHWAAB, Reges Toni. "As razões de um conceito". In TRIGUEIRO, André (org.). Jornalismo Ambiental: desafios e reflexões. Porto Alegre: Dom Quixote, 2008.

MASSIERER, Carine; LOOSE, Eloisa Beling; SCHWAAB, Reges. Jornalismo Ambiental: caminhos e descaminhos. In: $8^{\circ}$ Encontro da Sociedade Brasileira de Pesquisadores em Jornalismo, São Luís, 2010.

HERSCOVITZ, Heloiza. Golbspan. “Análise de conteúdo em jornalismo”. In LAGO, Cláudia; BENETTI, Marcia (org.). Metodologia de pesquisa em Jornalismo. Petrópolis: Vozes, 2007.

KOCH, Ingedore. Villaça. Desvendando os segredos do texto. São Paulo: Cortez, 2002.

MORAES, C. H. Jornalismo no Médio Alto Uruguai: aproximações ao objeto, reflexões metodológicas e notas de pesquisa. In: V Encontro Nacional de Pesquisadores em Jornalismo, Aracaju, 2007.

MORAES, Claudia Herte, CORRÊA, Aline. Michelle. Ferreira. "Entre o susto e o esquecimento: Jornalismo Ambiental na lógica da indústria da informação". In TRIGUEIRO, André (org.). Jornalismo Ambiental: desafios e reflexões. Porto Alegre: Dom Quixote, 2008. 
PLATÃO, Savioli. FIORIN, Francisco. Lições de texto: leitura e redação. São Paulo: Ática, 2000.

TRIGUEIRO, André. Mídia: Meio ambiente na idade mídia. In TRIGUEIRO, André (coord.). Meio Ambiente no século 21: 21 especialistas falam da questão ambiental nas suas áreas de conhecimento. Campinas: Armazém do Ipê, 2008.

ONU. A ONU e o meio ambiente. http://www.onu.org.br/a-onu-em-acao/a-onu-e-o-meioambiente/. Acessado em 28 abr 2013. 